\title{
Competências para o trabalho nos Consultórios na Rua
}

| ${ }^{1}$ Marcelo Pedra Martins Machado, ${ }^{2}$ Elaine Teixeira Rabello |

Resumo: A criação das equipes de Consultórios na Rua (eCR) recoloca em discussão a questão da formação em saúde, em especial para o trabalho com a população em situação de rua (PSR). Este estudo teve como objetivos: identificar os componentes de competências utilizadas pelos profissionais (conhecimentos, habilidades e atitudes); sistematizar e associar os componentes de tais competências; propor a síntese dos elementos mapeados em competências para o trabalho nas eCR. De abordagem qualitativa, a pesquisa foi realizada em duas fases de coleta e sistematização de dados: a realização de três grupos focais com as eCR do Distrito Federal; a construção de consenso sobre competências para trabalho na eCR em consulta a expertos, das cinco regióes do país, utilizando o Método Delphi. Foram elencados 25 conhecimentos, 37 habilidades e 16 atitudes como componentes das competências para o trabalho nas eCR. A partir dos 30 elementos mais votados pelos expertos, foram propostas três competências: uma no campo da clínica/cuidado, outra no campo do processo de trabalho e a última, sobre o trabalho em rede. Finalmente, discutiram-se os elementos que não foram incluídos na lista principal e como estes podem contribuir para o debate sobre a atuação dos profissionais em saúde para a atuação no Sistema Único de Saúde (SUS) e junto à PSR.

> Palavras-chave: equipes de Consultório na Rua; competências profissionais; formação para o SUS.

\footnotetext{
1 Instituto de Medicina Social, Universidade do Estado do Rio de Janeiro. Rio de Janeiro-RJ, Brasil (marcelopedra@bol.com.br). ORCID: 0000-0001-9520-2972

2 Instituto de Medicina Social, Universidade do Estado do Rio de Janeiro. Rio de Janeiro-RJ, Brasil (mcarelaine@gmail.com). ORCID: 0000-0002-8324-1453
}

Recebido em: 05/02/2018 Revisado em: 10/07/2018 Aprovado em: 08/10/2018 


\section{Introdução}

A Política Nacional de Atenção Básica (PNAB) tem se apresentado como uma importante estratégia de enfrentamento das singulares iniquidades históricas no que tange às questôes de saúde da população brasileira (MENDES, 2010). Com a criação das equipes de Atenção Básica (AB) específicas, como as equipes de Consultórios na Rua (eCR) - além das ribeirinhas e fluviais —, diversas questóes estão sendo introduzidas: organização do processo de trabalho destes serviços, sua inserção nas redes de atenção à saúde e a questão da formação e qualificação de profissionais de saúde com habilidades e competências adequadas e oportunas para atuar em um contexto tão singular.

O presente estudo busca sistematizar as competências necessárias para o trabalho nas eCR, na $\mathrm{AB}$ a partir da identificação de conhecimentos, habilidades e atitudes demandadas nas práticas de eCR já em atividade, bem como propor uma síntese destes elementos, considerando a opiniáo de expertos e gestores com experiência em trabalho com população de rua em todo o território nacional.

No âmbito das políticas públicas no Brasil, essa população ganhou maior visibilidade com a criação da Política Nacional para População em Situação de Rua (PNPR). Em sequência à PNPR, a PNAB criou as eCR como uma estratégia de cuidado integral às pessoas em situação de rua. As eCR são equipes multiprofissionais ${ }^{1}$ que prestam atenção integral à saúde tanto na rua quanto na Unidade Básica de Saúde (UBS) onde está lotada. Estas equipes lidam com os diferentes problemas e necessidades de saúde da população em situação de rua, desenvolvendo ações compartilhadas e integradas também com as equipes dos Centros de Atenção Psicossocial (CAPS), dos serviços de urgência e emergência e de outros pontos de atenção à saúde e da rede do território, de acordo com a necessidade do usuário (BRASIL, 2012c). As eCR integram o componente Atenção Básica da Rede de Atenção Psicossocial (RAPS), desenvolvendo suas atividades de forma itinerante e, quando necessário, construindo açôes em parceria com as equipes das UBSs do território. Vale ressaltar que nas atividades das equipes está incluído todo o rol de cuidados primários, com ênfase na busca ativa aos usuários de álcool e outras drogas e na lógica da redução de danos (BRASIL, 2011).

As portarias do Ministério da Saúde no 122 e no 123, de 25 de janeiro de 2012, estabelecem as diretrizes de organização e funcionamento das eCR. Hoje, segundo 
o Cadastro Nacional de Estabelecimentos de Saúde (CNES), existem 165 eCR no Brasil (CNES, 2018). As equipes têm carga horária mínima de 30 horas semanais, tendo o horário de funcionamento adequado às demandas das pessoas em situação de rua, podendo ocorrer em período diurno e/ou noturno em todos os dias da semana (BRASIL, 2012a). Cada equipe é responsável por uma população de no mínimo 80 e no máximo mil pessoas em situação de rua. Atualmente existem aproximadamente mil profissionais atuando nestas equipes, entre as categorias profissionais mais presentes estão os enfermeiros, psicólogos, assistentes sociais, agentes de ação social, médicos e odontólogos (CNES, 2018).

Pesquisa bibliográfica sobre o tema ${ }^{2}$ realizada com o descritor "Consultório na Rua” retornou 15 artigos na Biblioteca Virtual em Saúde (BVS), apresentando como estado da arte na produção acadêmica o foco em questóes como acesso a serviço de saúde, HIV/AIDS, transtornos mentais/saúde mental, uso de álcool e outras drogas e estigma, sendo, em sua maioria, relatos de experiências. Não há indicação de diretrizes para a organização do trabalho da eCR ou para a formação de profissionais voltados para essa população. Já no campo da produção oficial (Ministério da Saúde), a mesma se mostrou reduzida sobre o tema e em especial quanto às práticas e à organização do processo de trabalho das equipes. Existem basicamente dois documentos disponíveis sobre o tema: o Manual de Cuidado à População de Rua (BRASIL, 2012c) e as Diretrizes, Metodologias e Dispositivos de População de RualeCR/RJ (UFF, 2014).

Os problemas de saúde demandados às equipes do Consultório na Rua têm origem em situaçóes complexas, com vários agravos e condiçôes de saúde combinados (tuberculose, HIV/AIDS, uso intenso de drogas, entre outros), cujas respostas necessitam de intervençôes articuladas entre os gestores, profissionais de saúde e diversos outros setores. Diante destas questôes, os profissionais de saúde assumem a função de buscar parcerias para o enfrentamento dos determinantes sociais do adoecimento, de modo a oferecer melhores respostas a essas pessoas, contribuindo de forma mais efetiva para o desempenho clínico-assistencial (BRASIL, 2012c).

Nesse contexto, a questão da formação de profissionais de saúde para o Sistema Único de Saúde (SUS) e para atuar em equipes de Atenção Básica, como as do Consultório na Rua, coloca-se como um nó crítico que, em parte, deriva das significativas mudanças na maneira de se compreender e agir sobre o processo saúde-doença experimentadas na saúde pública brasileira, desde a implantação do 
SUS em 1988. Considerando-se profissionais de saúde todas as categorias de nível superior elencadas pelo Conselho Nacional de Saúde na Resolução no 218, de 06 de março de 1997, historicamente vem se reproduzindo uma visão centrada nas técnicas biomédicas, e a ênfase nos procedimentos superou amplamente o pensar a saúde. Ceccim e Feuerwerker (2004) alertam para a necessidade de se deslocar o eixo biomédico para o da atenção interdisciplinar, conectando os princípios do SUS com estratégias de alteração de perfis profissionais. No caso dos trabalhadores que compóem as eCR, torna-se central o debate sobre as competências necessárias para atuar em consonância com as necessidades de cuidado a esta população e a habilidade de trabalho colaborativo e em rede.

A partir desse entendimento, o presente estudo objetivou mapear e apontar as competências (a partir dos elementos de conhecimentos, habilidades e atitudes) necessárias para a atuaçáo de trabalhadores na eCR. Para isto, consideraram-se como fonte de dados primários para essa composição a opinião, a expertise e a avaliação de trabalhadores de eCR de todo o país e de profissionais de saúde e gestores do SUS com notório acúmulo sobre esta temática e recorte populacional. Quando se trazem essa discussão e suas ferramentas para a formação de trabalhadores para o SUS, tem-se aqui a exigência de aproximação dos campos do trabalho e da educação, conduzindo a concepção de competência para o lugar de resultante da relação entre o mundo de aprendizagem e o mundo do trabalho, fazendo com que a natureza do conhecimento seja explicitada pelo contexto da aquisiçáo na forma do seu uso (AGUIAR; RIBEIRO, 2010).

O referencial conceitual de competência que foi adotado como base para a discussão deste estudo é o de Phillipe Perrenoud. Para este autor, o conhecimento do profissional é construído através de sua experiência e é definido como o conjunto de esquemas de pensamento e de ação de que um determinado sujeito dispõe (PERRENOUD, 2001). A construção deste processo irá determinar suas percepçôes, interpretaçóes e, consequentemente, as decisóes tomadas, com o propósito de interagir com as questóes e os problemas reais do trabalho cotidiano (VALENTE; VIANA, 2009).

A decomposição do conceito de competência em conhecimentos, habilidades e atitudes, tal como explorada a seguir, foi adotada estrategicamente para realizar o campo proposto neste trabalho, a partir de uma matriz analítica da ideia de 
competência que, de forma alguma, propóe a decomposição stricto sensu do conceito. Segundo Saupe et al. (2006, p. 33), em uma visão mais analítica da ideia de competência, esta conteria em si os elementos do conhecimento, da habilidade e da atitude. Conhecimento é o conjunto de informaçôes que possibilita ao profissional o domínio do "saber", do registro e acesso a informaçôes de dada esfera ou temática. Já as habilidades são o conjunto de experiências que fornecem ao profissional o domínio do "saber fazer, saber realizar", seja no sentido psicomotor (fazer um procedimento manual) ou cognitivo (solucionar problemas ou operar esquemas de decisão). As atitudes são o conjunto de comportamentos que confere ao profissional o domínio ético e afetivo de um "saber ser e saber conviver". É a partir desta matriz analítica do conceito de competência que foi construído o campo de investigação.

Retomando a visão de competência de Perrenoud (1999a, p. 7), esta significa "uma capacidade de agir eficazmente em um determinado tipo de situação, apoiada em conhecimentos, mas sem limitar-se a eles", apontando que no enfrentamento de um problema vários serão os recursos cognitivos complementares mobilizados, entre eles os conhecimentos. Avançando ainda mais na conceituação sobre competência, Perrenoud (1999b) a descreve como a maneira eficaz de interagir com situaçóes semelhantes, ou análogas, articulando recursos cognitivos com saberes, informações, capacidades, valores e atitudes, de forma criativa e associada.

Quando se transpóe essa discussão para o terreno da formação e do trabalho em saúde, as competências surgem como recursos demandados aos profissionais, sob a forma de conhecimentos, habilidades e atitudes fundamentais para consolidar os Consultórios na Rua, a Atenção Básica e o SUS, processos que operam entre os conhecimentos técnicos e o contexto social, podendo com esse movimento contribuir para a ampliação do potencial resolutivo da $\mathrm{AB}$ (SAUPE et al., 2006).

\section{Percurso da investigação}

Este estudo utilizou duas estratégias de coleta e sistematização de dados, ambas em perspectiva qualitativa, realizadas em dois momentos. Para uma primeira aproximação com a realidade do cotidiano de trabalho das eCR, três grupos focais foram compostos por 15 profissionais, no total, das três equipes de Consultório na Rua atuantes no Distrito Federal (DF). Em um segundo momento, foi realizada uma consulta técnica a expertos em todo o território nacional, seguindo o Método Delphi. 
Os grupos focais no DF foram orientados pela apresentação de tópicos-guia, estimulando a conversa sobre questóes referentes ao dia a dia do trabalho das equipes que pudessem suscitar comentários acerca das competências necessárias para o trabalho nas eCR. Cada grupo focal teve duração de uma hora a, no máximo, uma hora e 30 minutos, e aconteceu em sala de atendimento ou de reuniáo dentro das unidades de saúde onde as equipes estâo lotadas. A escolha de levantar os primeiros dados junto às equipes se deu pelo fato de ainda não haver vasta publicação científica, ou mesmo relatórios técnicos sobre o tema em questão que pudesse subsidiar a primeira consulta aos expertos. Ou seja, foi a partir da análise das falas dos trabalhadores dos Consultórios na Rua do Distrito Federal que se propôs um conjunto de conhecimentos, habilidades e atitudes que viabilizaram a construção do primeiro instrumento do Método Delphi.

De posse de elementos levantados pelos trabalhadores dos grupos focais, foi realizada uma consulta aos expertos através do Método Delphi. Este constitui uma ferramenta de pesquisa qualitativa que busca um consenso de opiniôes de um grupo de especialistas, por meio de uma consulta técnica a respeito de determinadas temáticas. Inicialmente concebido como instrumento para uso militar, posteriormente foi apropriado para investigaçóes nos campos empresariais, sociológicos e da saúde, objetivando buscar opiniôes coletivas de atores qualificados, consensos de opinióes, entendendo consensos como a consolidação do julgamento dos especialistas (CAMPOS et al., 2010).

Turoff e Linstone (1975) destacam que o Delphi também pode se caracterizar como um método de estruturação de processos de comunicação em grupo, permitindo que um grupo de especialistas interaja com problemas complexos. Existem outros usos, na perspectiva destes dois autores, para os quais o método pode servir, entre eles: a coleta de dados atuais e históricos não conhecidos ou não disponíveis; o exame do significado de eventos históricos; a avaliação de possíveis alocaçôes de recursos; o planejamento no campus universitário e desenvolvimento de currículo; a combinação da estrutura de um modelo; a distinção e o esclarecimento das motivações humanas reais e percebidas; e a exposição de prioridades de valores pessoais e metas sociais.

Entre as vantagens apresentadas pelo método estão: realizar previsóes em áreas e temas carentes de dados históricos; utilizar um grupo de especialistas para analisar um determinado tema; possibilitar, através do anonimato, que o status do respondente 
não influencie a pesquisa; e otimizar custos por utilizar o e-mail como estratégia de reunir os especialistas. Como desvantagens são apresentadas questóes como: a excessiva dependência dos resultados em relação à escolha e à experiência do grupo de especialistas selecionados; a possibilidade de forçar o consenso de maneira indevida; a possibilidade de construção de um questionário com perguntas ambíguas; a seleção das amostras e a análise dos resultados de forma inadequada estatisticamente; e a dificuldade com a devolução dos questionários pelos especialistas (CAMPOS et al., 2010).

São estabelecidas três condições básicas para a construção do consenso via Método Delphi: o anonimato dos respondentes, a representação estatística da distribuição dos resultados e o feedback de respostas do grupo para reavaliação nas rodadas subsequentes (MARTINO, 1993). As rodadas sucessivas e trocas de informações são consideradas fundamentais para a obtenção de um grau satisfatório de convergência nas proposiçóes, pois desta forma os respondentes podem rever suas posiçôes anteriores frente às reorganizaçôes propostas pelo grupo, sendo o consenso o produto deste processo (CAMPOS et al., 2010).

De um modo geral, o Método Delphi apresenta a seguinte configuração (MUNARETTO; CORRÊA; CUNHA, 2013):

a) O formato é, geralmente, uma lista de itens (no caso do presente estudo, elementos de competência — conhecimento, habilidade, atitude) a ser apreciada pelos profissionais especialistas no modo individual, sessóes de grupos interativas ou on-line (no caso do presente projeto, por e-mail);

b) A lista consiste em uma série de itens (neste caso, elementos de competência - conhecimento, habilidade, atitude - levantados anteriormente via grupos focais) em escalas quantitativas ou qualitativas;

c) Os itens que compóem a lista a ser apreciada podem ser gerados pelo pesquisador, pelos participantes especialistas ou por ambos (no caso presente, foram gerados em momento anterior, por grupos focais com profissionais);

d) O e-mail com a lista apresenta algumas instruções sobre os itens e como comentá-los;

e) O e-mail com a lista é apresentado aos participantes especialistas, em duas ou mais rodadas (chegando a no máximo quatro);

f) Cada momento de interação é seguido de alguma forma de análise dos dados e também de um feedback estatístico, geralmente envolvendo medidas de tendência central, medidas de dispersão, além da possibilidade de apresentar a distribuição de frequência absoluta das respostas de cada item do questionário. 
Os participantes da consulta técnica por meio do Método Delphi foram indicados por técnicos do Departamento de Atenção Básica do Ministério da Saúde (DAB/ MS) que acompanham as eCR e a formação dos profissionais das mesmas, além das indicaçôes da coordenação do Curso de Cuidado à População em Situação de Rua, com ênfase nos Consultórios na Rua, realizado pela Escola Nacional de Saúde Pública (ENSP/Fiocruz), com duas ediçôes nacionais (2014 e 2016). O convite, o registro do consentimento via Termo de Consentimento Livre e Esclarecido (TCLE) e a efetiva circulação dos instrumentos do Método Delphi foram realizados por e-mail.

A lista indicada pelas duas instituiçôes (DAB/MS e ENSP/Fiocruz) continha 20 sujeitos, todos trabalhadores das redes do Sistema Único de Saúde (SUS) e do Sistema Único de Assistência Social (SUAS), sendo estes profissionais gestores e educadores/ formadores com experiência no cuidado/atenção, na gestão e na formação junto à população em situação de rua. Para determinar o número de sujeitos de pesquisa nesta etapa, foi considerado o número total de 165 Consultórios na Rua no Brasil. Também foi levado em consideração que o trabalho junto à população em situação de rua é uma prática recente — tendo começado no final dos anos 90 —, sendo que, enquanto políticas públicas estruturadas, datam de 2010. Deste modo, avaliouse que 20 profissionais, contemplando todas as regióes do país, era um número suficiente para a sustentação do método.

Os critérios de inclusão no grupo de expertos foram: trabalhar ou ter trabalhado por mais de dois anos junto à população em situação de rua em eCR ou em serviços que se relacionem diretamente com as eCR - Centro Pop, CREAS, abrigamento institucional, CAPS II, CAPS III, CAPS AD e CAPS AD III - e/ou exercer o trabalho no campo do cuidado, da gestão ou da educação/formação.

\section{Construção de (con)sensos sobre o trabalho nas equipes de Consultório na Rua}

Para a primeira rodada da consulta, foi enviado um formulário via e-mail para traçar o perfil dos expertos (idade, sexo, tempo de formação, categoria profissional, pós-graduaçôes, campo de atuação, nível de atuação e produção acadêmica). No mesmo e-mail foi enviada a primeira lista para avaliação e comentários dos expertos sobre os conceitos pretendidos, oriundos da análise do material produzido pelos grupos focais sobre conhecimentos, habilidade e atitudes para o trabalho nas eCR. 
O primeiro e-mail enviado para os 20 expertos indicados foi respondido e retornado por todos aos pesquisadores no espaço de 30 dias. Nesse momento, foi possível traçar um perfil dos respondentes (quadro 1).

Quadiro 1. Dados sociodemográficos e de trabalho dos respondentes (continua)

\begin{tabular}{|c|c|}
\hline Idade média & 38 anos (entre 27 e 59 anos) \\
\hline Mediana da idade dos respondentes & $36 / 37$ anos \\
\hline Escolaridade & $\begin{array}{c}\text { Todos os respondentes têm, ao menos, o } \\
\text { ensino superior completo }\end{array}$ \\
\hline Média de tempo de formação & 12,7 anos (entre 2 e 33 anos) \\
\hline $\begin{array}{l}\text { Média do tempo de atuação junto à } \\
\text { populaçáo em situação de rua }\end{array}$ & 6 anos (entre 15 e 2 anos) \\
\hline \multicolumn{2}{|c|}{ Formação } \\
\hline Psicologia & 8 \\
\hline Enfermagem & 5 \\
\hline Serviço Social & 4 \\
\hline Medicina & 3 \\
\hline \multicolumn{2}{|c|}{ Maior titulaçáo } \\
\hline Especialização & 10 \\
\hline Mestrado & 6 \\
\hline Doutorado & 2 \\
\hline \multicolumn{2}{|c|}{ Serviço de atuação } \\
\hline eCR & 10 \\
\hline Universidade & 3 \\
\hline SMS & 2 \\
\hline CAPS & 2 \\
\hline Serviços da Assistência Social & 2 \\
\hline UBS & 1 \\
\hline
\end{tabular}

continua... 


\begin{tabular}{|c|c|c|}
\hline Região do país & No de municípios com eCR & $\begin{array}{c}\text { No de respondentes } \\
\text { ao questionário }\end{array}$ \\
\hline Sudeste & 41 municípios com eCR & 8 trabalhadores \\
\hline Nordeste & 17 municípios com eCR & 4 trabalhadores \\
\hline Sul & 11 municípios com eCR & 4 trabalhadores \\
\hline Centro-Oeste & 8 municípios com eCR & 2 trabalhadores \\
\hline Norte & 4 municípios com eCR & 2 trabalhadores \\
\hline \multicolumn{3}{|c|}{ Cidades de atuaçáo dos respondentes } \\
\hline \multicolumn{2}{|c|}{ Anápolis-GO } & 1 \\
\hline \multicolumn{2}{|c|}{ Belo Horizonte-MG } & 1 \\
\hline \multicolumn{2}{|c|}{ Caxias do Sul-RS } & 1 \\
\hline \multicolumn{2}{|c|}{ Curitiba-PR } & 1 \\
\hline \multicolumn{2}{|c|}{ Goiânia-GO } & 1 \\
\hline \multicolumn{2}{|c|}{ Imperatriz do Maranhão-MA } & 1 \\
\hline \multicolumn{2}{|c|}{ Joinville-SC } & 1 \\
\hline \multicolumn{2}{|c|}{ Juiz de Fora-MG } & 1 \\
\hline \multicolumn{2}{|c|}{ Londrina-PR } & 1 \\
\hline \multicolumn{2}{|c|}{ Macapá-AP } & 2 \\
\hline \multicolumn{2}{|c|}{ Maceió-AL } & 1 \\
\hline \multicolumn{2}{|c|}{ Petrolina-PE } & 1 \\
\hline \multicolumn{2}{|c|}{ Rio de Janeiro-RJ } & 4 \\
\hline \multicolumn{2}{|c|}{ Salvador-BA } & 1 \\
\hline \multicolumn{2}{|c|}{ São Paulo-SP } & 2 \\
\hline
\end{tabular}

Fontes: autoria própria (2017) e Cadastro Nacional de Estabelecimentos de Saúde (CNES), maio de 2018.

Os expertos interagiram, nesta primeira rodada, com 78 elementos, sendo estes 25 conhecimentos, 36 habilidades e 17 atitudes propostas a partir dos elementos obtidos nos grupos focais de aproximação. Foi solicitado a cada experto que avaliasse esta lista atribuindo a cada item notas de 1 a 7 , em que um (1) significava que o item era pouco importante e sete (7) que era fundamental às necessidades e à 
pertinência para o trabalho em um Consultório na Rua. Além disso, foi dado espaço à possibilidade de haver outros conhecimentos, habilidades e atitudes que não haviam sido contemplados, que poderiam ser registrados em escrita livre. Neste espaço também lhes era facultado fazer comentários quanto à compreensão do item, à classificação do mesmo como conhecimento, habilidade ou atitude e, ainda, em relaçáo ao texto descritivo em si.

Após essa primeira devolução, as respostas foram analisadas de maneira quantitativa e qualitativa para elencar as principais categorias presentes, verificando quais mantinham maior consenso entre os expertos. Os critérios para a seleção e hierarquização dos itens avaliados pelos expertos foram:

1 $\quad$ Maior número de notas máximas (7);

2o Maior número total de pontos atribuídos ao item;

3o Não ter havido sugestão de mudança de título do item ou outra sugestão qualquer de inclusão, ou mesmo menção de dificuldade de entendimento (por parte do respondente) do item.

Após essa estratificação dos resultados da primeira rodada, foi proposta a segunda rodada do instrumento, cujo objetivo seria hierarquizar — do mais ao menos importante — os dez elementos (conhecimentos, habilidades e atitudes) melhor pontuados na etapa anterior. A última rodada, propondo que os participantes hierarquizassem os 30 elementos de consenso como os mais relevantes, tinha por objetivo trazer à tona o grau de priorização destes elementos na opinião dos expertos. O intervalo temporal entre a primeira e a segunda rodada foi de 20 dias. Nesta nova rodada, o instrumento foi enviado aos mesmos 20 expertos; destes, 19 retornaram com suas avaliaçôes em um período de 21 dias.

O critério para a hierarquização final da lista, após a segunda rodada, foi o maior número de expertos votantes no item para uma específica posição no ranking hierárquico $\left(1^{\circ}, 2^{\circ}, 3^{\circ}\right.$ e assim sucessivamente). O critério de desempate, se necessário, foi o maior número de expertos votantes para que o item ocupe a posição no ranking hierárquico imediatamente posterior/seguinte.

Partindo destes critérios, os dez conhecimentos mais pontuados após a primeira rodada do instrumento Delphi foram novamente expostos aos expertos a fim de que recebessem agora as indicaçóes em grau de importância entre eles, para subsequente classificação em hierarquização, ficando dispostos conforme demostrado no quadro 2. 
Quadro 2. Os dez conhecimentos priorizados após a segunda rodada

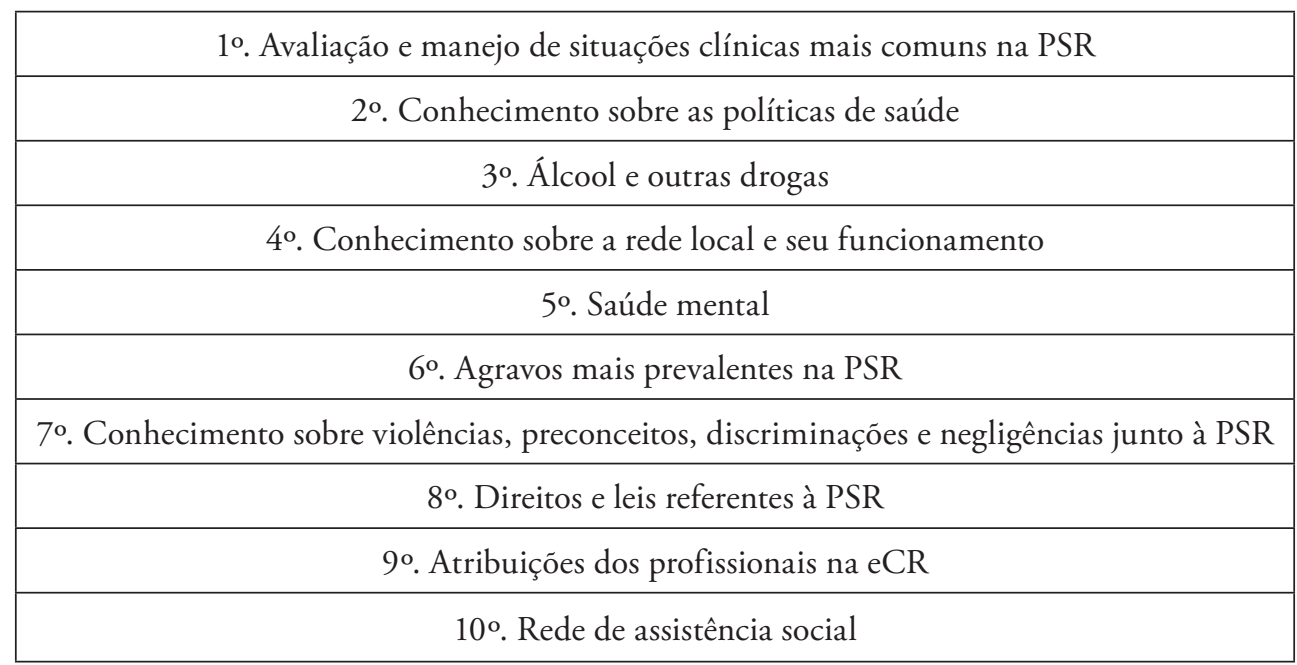

Fonte: os autores, 2017.

Da mesma forma, as dez habilidades que receberam as maiores pontuaçóes após a primeira rodada entre os expertos foram expostas a mais uma rodada via e-mail para que recebessem novas indicaçóes de grau de importância entre eles, para uma nova classificação em hierarquização (quadro 3).

Quadro 3. As dez habilidades priorizadas após a segunda rodada

\begin{tabular}{|c|}
\hline 1a. Escutar \\
\hline 2a. Criar vínculos e acolher a PSR \\
\hline $3^{\mathrm{a}}$. Abordar a PSR \\
\hline $4^{\text {a }}$. Trabalhar com a redução de danos \\
\hline 5a. Levantar e vincular as demandas da PSR \\
\hline 6a. Atender da perspectiva da atenção integral \\
\hline 7a. Trabalhar em equipes multiprofissionais \\
\hline 8a. Comunicação interpessoal \\
\hline 9a. Sistematizar e discutir casos \\
\hline 10a. Mediar o acesso junto aos serviços de saúde \\
\hline
\end{tabular}

Fonte: os autores, 2017. 
A seguir, as dez atitudes mais bem pontuadas após a primeira rodada do e-mail do instrumento Delphi para que recebessem uma segunda avaliação e classificação por grau de importância pelos expertos (quadro 4).

Quadiro 4. As dez atitudes priorizadas após a segunda rodada

\begin{tabular}{|c|}
\hline $1^{\text {a }}$. Respeitar a liberdade do usuário \\
\hline 2a. Trabalhar de forma humanizada \\
\hline $3^{\text {a }}$. Ter credibilidade junto à PSR \\
\hline 4a. Resiliência \\
\hline 5a. Adaptação a novas situaçóes/lidar com situaçóes imprevistas \\
\hline 6a. Disponibilidade para se relacionar \\
\hline 7a. Ser empático (colocar-se no lugar do outro) \\
\hline 8a. Permanecer sensível, paciente e aberto diante do outro \\
\hline 9a. Saber lidar com a frustração e impotência gerada pelo trabalho com a PSR \\
\hline 10a. Saber lidar com o preconceito \\
\hline
\end{tabular}

Fonte: os autores, 2017.

Tão importante quanto discutir o consenso entre os elementos elencados como essenciais é refletir sobre aqueles que ficarão de fora da priorização após as rodadas de consulta aos especialistas. Entre os 48 elementos não classificados como prioritários pelos expertos, alguns merecem ser problematizados por ajudarem no cotejamento do que vem sendo preconizado nos documentos oficiais, que apresentam insumos para definição de competências e atuação profissional.

Entre estes casos estáo os conhecimentos sobre feridas e curativos ( $18^{\circ}$ de 25 itens) e sobre o uso de protocolos clínicos (21ํ de 25 itens), mesmo estando próximos à questão da resolutividade, que foi um tema presente nos grupos focais e nas consultas via Delphi. Outro elemento bem significativo e que figurou na antepenúltima posição é o conhecimento sobre a sistematização do processo de trabalho em saúde (23 de 25 itens), sugerindo haver aqui uma aposta demasiada no improviso, que pode, inclusive, ser fruto das lacunas deixadas pela formação profissional para o desenvolvimento de competências que permitam a sistematização de um processo de trabalho em um contexto de atuação pouco conhecido pelos trabalhadores. Deste 
modo, um processo de trabalho não sistematizado pode deixar a equipe por demais exposta a um funcionamento sem a construção de sua história com a PSR, com suas próprias ofertas de cuidado e com a rede do território.

Entre as habilidades que chamaram a atenção por terem sido preteridas na lista principal dos expertos estão as que propóem o compartilhamento sistemático com os demais serviços do território e que podem ampliar as chances de coletivizar as questôes trazidas pela PSR. Assim, "construir relaçôes com a rede local” (15 de 36 itens) e "criar uma rotina de reuniōes intersetoriais" ( $31^{\circ}$ de 36 itens) não foram elencadas entre as mais importantes. Esta última, especificamente, recoloca de modo significativo a questão das rotinas necessárias para contribuir na organização do processo de trabalho da equipe, uma vez que as reuniōes intersetoriais poderiam servir para viabilizar trocas mais efetivas sobre os casos com a rede local. Isto porque sabe-se que as articulaçóes intersetoriais podem definir os limites de resolutividade de cada Consultório na Rua, promovendo um maior entendimento sobre as necessidades da populaçáo atendida.

Ainda versando sobre as habilidades que não foram contempladas como as mais importantes na presente investigação, observa-se que o processo de trabalho das equipes aparece de forma recorrente, como é visto no item "realizar reuniôes de equipe" (130 de 36 itens). Tal aspecto se contradiz ao que se espera dos profissionais, uma vez que o trabalho em equipe se configura como uma estratégia central (mesmo que com periodicidade mais espaçada) para a produção de horizontes comuns entre os trabalhadores, a clínica promovida e a relação com os usuários e a rede. As reuniōes assumem importante papel para que um conjunto de trabalhadores se torne uma equipe de saúde (BRASIL, 2011; BRASIL, 2012c; BRASIL, 2013). Do mesmo modo, e ainda mais para o final da lista, estão "planejar as açóes da equipe" (23ํ de 36 itens) e "construçáo de memória institucional" (35 de 36 itens), ambas habilidades fundamentais para a organização e continuidade das açôes da equipe.

Ainda sobre o processo de trabalho, não foi elencada como prioridade a habilidade de "realizar consulta compartilhada" (30 de 36 itens). Para um Consultório na Rua, a referida habilidade pode se constituir como um mecanismo de apoio matricial entre as diversas categorias profissionais da equipe, além de ofertar ao usuário (geralmente com problemas e demandas complexas) uma modalidade de atendimento ampliada (UFF, 2014). Um elemento presente na trajetória de constituição do campo da Saúde 
Mental, mas ainda sem grande debate na Atenção Básica, é justamente a habilidade de "construir espaços de supervisão" (290 de 36 itens) que, mesmo constando no final da lista, pode nos chamar a atenção para este ponto ainda sem literatura e construção específica na $\mathrm{AB}$.

No campo da formação, a habilidade de "promover a Educação Permanente para os trabalhadores" (270 de 36 itens) aparece no fim da lista. Trata-se de uma estratégia de qualificação dos trabalhadores e do processo de trabalho fartamente citado pela literatura (CECCIM; FEUERWERKER, 2004; CECCIM, 2005) e por diversas políticas públicas de saúde (BRASIL, 2011), porém, aqui, foi deixada longe do rol de prioridades. Dentro do debate sobre a formação, outra habilidade que pode ser uma tática para avançar - tanto na qualificação de trabalhadores e do processo de trabalho quanto na construção de uma agenda de formação de alunos/trabalhadores mais próximos da realidade e das exigências dos cidadãos brasileiros e do SUS — é a de "construir relação com instituições de ensino e pesquisa (estágio e formação em serviço/residências)" (36º de 36 itens) que, no contexto das prioridades, foi colocada em último lugar na lista geral.

Em outra direçáo, a habilidade de "contribuir na construção de autonomia do usuário" também foi colocada em segundo plano enquanto "o empoderamento e a emancipação da população em situação de rua" (210 de 36 itens) ficou próxima da metade da lista. Ter como horizonte de trabalho a construção de autonomia e processos emancipatórios junto aos usuários é um ponto de partida e de chegada de suma importância não só para as $\mathrm{eCR}$, mas para o trabalho em saúde de uma maneira geral.

As atitudes que merecem comentários, entre as 17 iniciais, por não terem sido escolhidas entre as prioritárias foram as de "sensibilizar os demais serviços da rede para acolher a eCR e a PSR" (13 de 17 itens) e a de "sensibilizar a comunidade para o trabalho desenvolvido pela eCR" (16 ${ }^{\circ}$ de 17 itens). Essas atitudes compreendem informar, esclarecer e tornar a rede e a comunidade sensíveis à missáo e às possibilidades de trabalho da equipe, o que pode facilitar que a PSR transite pelos serviços públicos da maneira mais autônoma possível, sem que tenha de recorrer à eCR para mediar o acesso aos serviços da rede. A manutenção dessas atitudes pode, também, ampliar as chances de a equipe problematizar junto à rede e à comunidade questôes de estigma e preconceito. 
Além disso, a também preterida atitude de "ter credibilidade junto à rede" (120 de 17 itens) traz, entre outras questóes, a discussão sobre a resolutividade da eCR, pois uma das formas de manter a credibilidade junto à rede é operando uma relação de parceria entre todos os usuários e os serviços. Isso inclui o compartilhamento e encaminhamento de usuários e coloca em destaque as possibilidades de interagir e ter ofertas concretas para os problemas demandados pela PSR. Dito de outro modo: se a eCR não conseguir ofertar concretamente açôes de cuidado para a população que atende e a maior oferta da equipe for o encaminhamento, provavelmente isso será um problema em potencial na construção da credibilidade junto à rede.

\section{Proposição de competências para o trabalho no Consultório na Rua}

A proposta deste estudo foi realizar o agrupamento dos elementos mapeados no percurso da pesquisa, através da consulta a expertos em trabalho nas eCR, traduzindo-os em competências para o trabalho no Consultório na Rua. No sentido de organizar os elementos oriundos do processo descrito anteriormente neste artigo, foram agrupados os dez itens priorizados para os conhecimentos, habilidades e atitudes na lista final do Delphi em três grandes dimensōes: clínica/cuidado, processo de trabalho e trabalho em rede.

Tais dimensôes são um exercício de agrupar as competências propostas em função de a relação de coerência que os elementos (conhecimentos, habilidades e atitudes) priorizados pelos participantes da pesquisa apresentaram entre si, produzindo uma leitura do cenário geral e um conjunto de sugestôes de competências para o trabalho nas eCR, conforme expomos a seguir.

A primeira dimensão que propomos aglutina competências relacionadas à clínica do cuidado, cujos elementos (conhecimentos, habilidades e atitudes) foram apontados pelos participantes como centrais à atençâo integral à PSR, definida aqui como a capacidade de articular conteúdos biológicos, psicológicos e sociais que subsidiem a atenção à saúde. Compreende também desde a escuta, abertura à agenda do outro e interpretação até a aplicação do conhecimento científico e outros saberes na área da saúde para resolução de problemas da população atendida. 
Quadro 5. Competências para o trabalho no Consultório na Rua - Dimensão: Clínica do Cuidado

\begin{tabular}{|c|c|c|c|}
\hline & & & COMPETÊNCIA \\
\hline \multirow{4}{*}{ 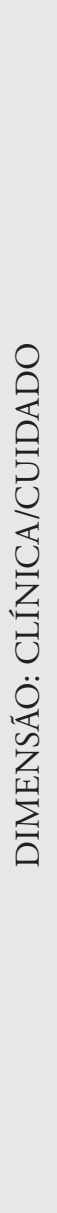 } & CONHECIMENTO & $\begin{array}{l}\text { Avaliação e manejo de situações } \\
\text { clínicas mais comuns entre a } \\
\text { PSR; } \\
\text { Álcool e outras drogas; } \\
\text { Saúde mental; } \\
\text { Agravos mais prevalentes entre } \\
\text { a população em situação de rua. }\end{array}$ & \multirow{3}{*}{$\begin{array}{l}\text { Atenção integral à } \\
\text { PSR: capacidade de } \\
\text { articular aspectos } \\
\text { biológicos, psicológicos } \\
\text { e sociais que subsidiem } \\
\text { a atenção à saúde. } \\
\text { Compreende desde a } \\
\text { escuta e abertura ao } \\
\text { outro, até a interpretação } \\
\text { e aplicação do } \\
\text { conhecimento científico } \\
\text { e outros saberes na área } \\
\text { da saúde para resolução } \\
\text { de problemas da } \\
\text { população atendida. }\end{array}$} \\
\hline & HABILIDADE & $\begin{array}{l}\text { Escutar; } \\
\text { Criar vínculos e acolher a PSR; } \\
\text { Abordar a PSR; } \\
\text { Atender na perspectiva da } \\
\text { atenção integral. }\end{array}$ & \\
\hline & ATITUDE & $\begin{array}{l}\text { Respeitar a liberdade do usuário; } \\
\text { Saber lidar com o preconceito. }\end{array}$ & \\
\hline & ATITUDE & $\begin{array}{l}\text { Adaptação a novas situaçóes/ } \\
\text { lidar com situaçóes imprevistas; } \\
\text { Disponibilidade para se } \\
\text { relacionar; } \\
\text { Ser empático (colocar-se no } \\
\text { lugar do outro); } \\
\text { Permanecer sensível, paciente e } \\
\text { aberto diante do outro. }\end{array}$ & \\
\hline
\end{tabular}

Fonte: os autores, 2017.

Seguindo a mesma lógica, foi possível identificar um segundo conjunto de competências concernentes ao processo de trabalho na equipe, como capacidade de organizar a gestão do trabalho e da clínica da eCR, privilegiando a utilizaçáo sistemática de informação (dados epidemiológicos, clínicos, territoriais, culturais, da rede local, etc.), valorizando o lugar do profissional em uma equipe multiprofissional, a gestão horizontal e a clínica colaborativa (pautada pela comunicação) e empregando a redução de danos como horizonte ético e técnico da equipe. 
Quadro 6. Competências para o trabalho no Consultório na Rua - Dimensão: Processo de Trabalho

\begin{tabular}{|c|c|c|c|}
\hline & & & COMPETÊNCIA \\
\hline \multirow{3}{*}{ 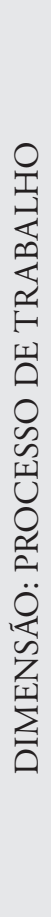 } & CONHECIMENTO & $\begin{array}{l}\text { As atribuiçóes de } \\
\text { profissionais na eCR. }\end{array}$ & \multirow{3}{*}{$\begin{array}{l}\text { Organização e operação do } \\
\text { processo de trabalho da eCR: } \\
\text { Capacidade de organizar a gestão } \\
\text { do processo de trabalho e da } \\
\text { clínica, privilegiando a utilização } \\
\text { sistemática de informação } \\
\text { (dados epidemiológicos, } \\
\text { clínicos, territoriais, culturais, } \\
\text { da rede local, etc.), valorizando } \\
\text { o trabalho multiprofissional, } \\
\text { a gestão horizontal e a clínica } \\
\text { colaborativa (pautada pela } \\
\text { comunicação), o trabalho } \\
\text { humanizado e empregando } \\
\text { a redução de danos como } \\
\text { horizonte ético e técnico da } \\
\text { equipe. }\end{array}$} \\
\hline & HABILIDADE & $\begin{array}{l}\text { Trabalhar com a } \\
\text { redução de danos; } \\
\text { Levantar e vincular as } \\
\text { demandas da PSR; } \\
\text { Trabalhar em equipes } \\
\text { multiprofissionais; } \\
\text { Comunicação } \\
\text { interpessoal; } \\
\text { Sistematizar e discutir } \\
\text { casos. }\end{array}$ & \\
\hline & ATITUDE & $\begin{array}{l}\text { Trabalhar de forma } \\
\text { humanizada; } \\
\text { Ter credibilidade junto } \\
\text { à PSR; } \\
\text { Resiliência. }\end{array}$ & \\
\hline
\end{tabular}

Fonte: os autores, 2017.

Por fim, um último grupo de competências relativas ao trabalho em rede aponta elementos referentes à organização, à mediação e à atenção em um sistema de saúde pública e à articulação das demais políticas públicas complementares ao trabalho da eCR. São conhecimentos, habilidades e atitudes ligados à capacidade de promover a abordagem integral do processo saúde-doença na população, alinhada às políticas públicas de atenção e à gestão da assistência, de modo a construir estratégias para superar estigmas e preconceitos junto à comunidade e aos demais serviços e contemplar ainda a promoção de acesso às demais políticas públicas. 
Quadro 7. Competências para o trabalho no Consultório na Rua - Dimensão: Trabalho em Rede

\begin{tabular}{|c|c|c|c|}
\hline & & & COMPETÊNCIA \\
\hline \multirow{3}{*}{ 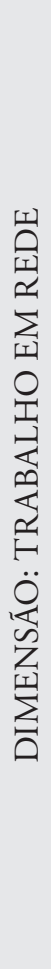 } & CONHECIMENTO & $\begin{array}{l}\text { Conhecimentos sobre as } \\
\text { Políticas de saúde; } \\
\text { Conhecimento sobre a rede } \\
\text { local e seu funcionamento; } \\
\text { Conhecimentos sobre as } \\
\text { violências, preconceitos, } \\
\text { discriminaçôes e } \\
\text { negligências junto à PSR; } \\
\text { Direitos e leis referentes à } \\
\text { PSR; } \\
\text { Rede de Assistência Social. }\end{array}$ & \multirow{3}{*}{$\begin{array}{l}\text { Organização, mediação } \\
\text { e atençáo em sistema } \\
\text { de saúde pública e } \\
\text { articulaçáo das demais } \\
\text { políticas públicas } \\
\text { complementares ao } \\
\text { trabalho da eCR: } \\
\text { capacidade de promover } \\
\text { abordagem integral do } \\
\text { processo saúde-doença na } \\
\text { população, alinhada às } \\
\text { políticas públicas de atenção } \\
\text { e gestáo da assistência, } \\
\text { construindo estratégias } \\
\text { para superar estigmas } \\
\text { e preconceitos junto à } \\
\text { comunidade e aos demais } \\
\text { serviços, compreendendo } \\
\text { ainda a promoção de acesso } \\
\text { às demais políticas públicas. }\end{array}$} \\
\hline & HABILIDADE & $\begin{array}{l}\text { Mediar o acesso junto aos } \\
\text { serviços de saúde. }\end{array}$ & \\
\hline & ATITUDE & $\begin{array}{l}\text { Saber lidar com a frustração } \\
\text { e impotência geradas pelo } \\
\text { trabalho com a PSR. }\end{array}$ & \\
\hline
\end{tabular}

Fonte: os autores, 2017.

A perspectiva de competência sintetizada por Perrenoud (1999b) aposta em posicionar o conceito para além da capacidade de articular conhecimentos. Inclui na dinâmica dessa construção as capacidades/habilidades e os valores e atitudes, o que permite pensar nas dimensôes propostas (clínica/cuidado, processo de trabalho e trabalho em rede), como os três grandes campos mapeados a partir das interpretaçóes dos grupos focais e das leituras e das escolhas dos expertos. Tal aposta, de reforçar a necessidade de que mais cursos (superiores ou de nível médio no campo da saúde) se proponham a construir currículos baseados em competência, exige a incorporação desta opção conceitual, ampliando o campo de disputas das diferentes ideologias que operam no campo da educação, porém com uma histórica e hegemônica prevalência das tradicionais, baseadas em conteúdos (AGUIAR; RIBEIRO, 2010). 
A perspectiva e a estratégia de decompor as competências em seus aspectos cognitivos, ou domínio do saber (conhecimentos), dos aspectos psicomotores, ou domínio do saber fazer (habilidades) e dos aspectos afetivos, ou o domínio do saber ser e saber conviver (atitudes) (SAUPE et al., 2006) possibilitaram explorar os elementos mapeados, privilegiando a coerência entre estes.

À parte essas três dimensóes elencadas, derivadas dos elementos de consenso entre os participantes via Delphi, merece destaque o fato de que uma parte significativa dos elementos mapeados junto aos trabalhadores e dos agrupamentos das dimensôes e competências propostos não se revelou como específico ou exclusivo para o trabalho junto à PSR, mas sim como elementos que fazem parte da atuação "desejável" de uma equipe de Atenção Básica, orientada pelos princípios e diretrizes gerais da $\mathrm{AB}$, contemplados na PNAB (BRASIL, 2011).

\section{Considerações finais}

Este estudo foi realizado no sentido de sistematizar as competências a partir dos elementos mapeados, na tentativa de manter a primazia do cotidiano vivido e narrado pelos trabalhadores, e não impor a lógica da gestão ou da academia como referência. Certamente, se de outro modo fossem operados os dados, poderiam surgir outros agrupamentos e, por consequência, outras competências. Os elementos mapeados, assim como as dimensóes resultantes de seus agrupamentos, têm em si a potência de iluminar a problematizaçáo de diversos temas, servindo como ponto de partida para outras discussóes mais diretamente relacionadas a cada um dos elementos elencados. Deste modo, o recorte sugerido pela proposição das competências apresentadas neste estudo não tem a intenção de ser único, final, ou esgotar, de forma alguma, a potência dos elementos mapeados. Estas sugestôes pretendem colaborar para a construção dos debates e das problematizaçóes no campo da formação e do trabalho em saúde, utilizando a noção de competência como estratégia para um diálogo oportuno entre as demandas e necessidades dos trabalhadores do SUS, em especial dos Consultórios na Rua.

É importante considerar a reduzida produção de conhecimento que, ao menos no período pesquisado, tem se dedicado sobretudo à descrição das características da PSR, aos modos de viver nas ruas, à exemplificação da experiência das equipes 
que trabalham junto a esta população e com foco no cuidado a usuários de álcool e outras drogas. Além disso, é apontado o descompasso entre as ofertas de qualificação acadêmica e as reais demandas das ruas que se apresentam aos trabalhadores.

A lista final de conhecimentos, habilidades e atitudes priorizadas nas escolhas dos expertos evidencia entre os sujeitos pesquisados um demasiado "prestígio" dos elementos que se conectam com a parte clínica. Neste contexto, defende-se o equilíbrio entre a clínica, o processo de trabalho e o trabalho em rede na tentativa de reverter ou escapar da priorização dos elementos mais ligados à dimensão clínica e emergencial do trabalho do Consultório na Rua, dimensão que tende sobretudo a hipertrofiar o trabalho da equipe na ação direta com o usuário, dando menor prestígio para os elementos que podem contribuir com a organização do processo de trabalho e a relação com outros serviços e políticas públicas. Se tomados em equilíbrio, a gestão, o processo de trabalho e o cuidado direto ao usuário tornam virtualmente possível que a equipe possa ofertar não só cuidado, mas também colaborar com o ordenamento e a regulação dos usuários pela rede, além de, pela via de processos de trabalho sistematizados, fortalecer por exemplo a educação permanente.

Enfim, é importante apontar um conjunto de agendas futuras de investigação, cuja abordagem o escopo, os limites e os recortes realizados pelo presente trabalho não possibilitaram, como: a clínica das eCR (presente em muitos dos elementos mapeados) e a produção de cidadania; a função de qualificação das demais equipes e serviços do território que a eCR pode proporcionar para garantia de acesso e continuidade do cuidado junto a essa população; e as chances que estas equipes têm de discutir e construir modelos menos hierárquicos de atendimento na $\mathrm{AB}$ e a partir dela; a própria questão da educação permanente na interface com o trabalho na eCR.

Por fim, os dados analisados e as proposiçóes discutidas a partir da revisão dos documentos oficiais do Ministério da Saúde, corroborando a fala dos trabalhadores das eCR entrevistados, explicitam significativa carência de informaçôes e orientaçôes mais específicas sobre estas equipes. Portanto, reconhecemos que este estudo escolheu focar na sistematizaçáo das competências identificadas pelos próprios trabalhadores. Porém, estamos cientes de que há implicaçôes e impactos possíveis também para a gestâo (esferas federal e municipal) e para esta política pública específica. ${ }^{3}$ 


\section{Referências}

AGUIAR, A. C. de; RIBEIRO, E. C. O. Conceito e avaliação de habilidades e competências na educação médica: percepçôes atuais dos especialistas. Revista Brasileira de Educação Médica, v. 34, n. 3, p. 371-78, 2010.

BRASIL. Conselho Nacional de Saúde. Resolução n. 218, de 6 de março de 1997. Reconhece as categorias profissionais de saúde de nível superior. Diário Oficial[da]República Federativa do Brasil, Brasília, DF, 5 maio 1997.

. Decreto no 7.053, de 23 de dezembro de 2009. Institui a Política Nacional para a População em situação de Rua e seu Comitê Intersetorial de Acompanhamento e dá outras providências. Diário Oficial[da]República Federativa do Brasil, Brasília, DF, 24 dez. 2009. Seção 1, p. 16.

. Ministério da Saúde. Portaria no 2.488, de 21 de outubro de 2011. Aprova a Política Nacional de Atenção Básica, estabelecendo a revisão de diretrizes e normas para a organização da Atenção Básica, para a Estratégia Saúde da Família (ESF) e o Programa de Agentes Comunitários de Saúde (PACS). Diário Oficial[da]República Federativa do Brasil, Brasília, DF, 24 out. 2011. Seção 1, p. 48.

. Ministério da Saúde. Portaria no 122, de 25 de janeiro de 2012. Define as diretrizes de organização e funcionamento das Equipes de Consultório na Rua. Diário Oficial[da]República Federativa do Brasil, Brasília, DF, 26 jan. 2012a. Seção 1, p. 46.

. Ministério da Saúde. Portaria no 123, de 25 de janeiro de 2012. Define os critérios de cálculo do número máximo de equipes de Consultório na Rua (eCR) por Município. Diário Oficial[da]República Federativa do Brasil, Brasília, DF, 26 jan. 2012b. Seção 1, p. 48.

Ministério da Saúde. Secretaria de Atenção à Saúde. Departamento de Atenção Básica. Manual sobre o cuidado à saúde junto a população em situação de rua. Brasília: Ministério da Saúde, 2012c.

. Ministério da Saúde. Secretaria de Atenção à Saúde. Política Nacional de Humanização. Brasília: Ministério da Saúde, 2013.

CADASTRO NACIONAL DOS ESTABELECIMENTOS DE SAÚDE (CNES). Disponível em: <http://cnes2.datasus.gov.br/Lista_Tot_Equipes.asp=>. Acesso em: maio 2018.

CAMPOS, R. T. O. et al. Oficina de construção de indicadores e dispositivos de avaliação: uma nova técnica de consensos. Estudos e pesquisas em psicologia. Rio de Janeiro, n. 1, p. 221-41, 2010.

UNIVERSIDADE FEDERAL FLUMINENSE (UFF). Diretrizes, metodologias e dispositivos do Pop Rua. Equipe de Consultório na Rua/Rio de Janeiro - Centro. 2014.

CECCIM, R. B.; FEUERWERKER, L. M. C. O Quadrilátero da Formação para a área da saúde: ensino, gestão, atenção e controle social. Physis: Revista Saúde Coletiva. Rio de Janeiro, v. 14, n. 1, p. 41-65, 2004. 
CECCIM, R. B. Educação permanente em saúde: desafio ambicioso e necessário. Interface comunicação, saúde, educação, v. 8, n. 16, p. 161-78, 2005.

MARTINO, J. P. Technological forecasting for decision marking. 3. ed. New York: Mac GrawHill Inc., 1993.

MENDES, E. V. As Redes de Atenção à Saúde. Ciência e Saúde Coletiva. Rio de Janeiro, v. 15, n. 5, p. 2297-305, 2010.

MUNARETTO, L. F.; CORRÊA, H. L.; CUNHA, J. A. C. Um estudo sobre as características do método Delphi e de grupo focal, como técnicas na obtenção de dados em pesquisas exploratórias. Revista de Administração da UFSM. Santa Maria, v. 6, n. 1, p. 9-24, 2013.

PAULON, S.; NEVES, R. Apresentação. In: PAULON, S.; NEVES, R. (Org.). Saúde mental na atençâo básica: a territorialização do cuidado. Porto Alegre: Sulina, 2013. 151 p.

PERRENOUD, P. Construir as competências desde a escola. Porto Alegre: Artes Médicas Sul, 1999a. . Construir competências é virar as costas aos saberes? Revista Pedagógica. Porto Alegre, n. 11, p. 15-9, 1999 b.

. Pedagogia diferenciada: das intençôes à ação. Porto Alegre: Artes Médicas, 2000.

. Escola Reflexiva e nova racionalidade. Porto Alegre: Artes Médicas, 2001.

SAUPE, R. et al. Conceito de competência: validação por profissionais de saúde. Saúde em Revista, Piracicaba, v. 8, n. 18, p. 31-7, 2006.

Avaliação das competências dos recursos humanos para a consolidação do sistema único de saúde no Brasil. Texto Contexto Enferm., v. 16, n. 4, p. 654-61, 2007.

TUROFF, M.; LINSTONE, H. A. The Delphi method. New York: Addison Wesley Publishing Company Inc., 1975.

VALENTE, G. S. C.; VIANA, L. O. Da formação por competências à prática docente reflexiva. Revista Iberoamericana de Educación, v. 48, n. 4, p. 132-140, 2009.

\section{Notas}

${ }^{1}$ Podem compor as eCR: médicos, enfermeiros, assistentes sociais, psicólogos, dentistas, terapeutas ocupacionais, profissionais de educação física, agentes comunitários de saúde, agentes sociais e auxiliares de consultório dentário.

${ }^{2}$ Busca realizada em 7 de dezembro de 2015 pelos autores deste estudo.

${ }^{3}$ M. P. M. Machado realizou a pesquisa com base na dissertação apresentada ao Mestrado Profissional em Administração em Saúde (2015/2017). E. T. Rabello realizou a revisão crítica do texto e orientou a dissertação que deu origem ao artigo 


\section{Abstract}

\section{Skill for the work in the Street Offices}

The creation of the Street Offices teams (eCR), to reassess issues related to the professional training for health, especially to working with people living on the streets (PSR). This study aimed at: identifying components of currently enacted competencies (knowledge, skills and attitudes); framing and associating these elements; proposing the synthesis of the mapped components as the core competencies for working in the eCR. With qualitative approach, this work assumed two phases for collecting and systematizing data: the execution of focus groups with three eCR from the Federal District; and the construction of consensus on competencies for work in the eCR, consulting 20 workers, managers and experts, from the five regions of the country, using the Delphi Method. Were considered as components of the competencies for the work at eCR: 25 knowledge, 37 skills, and 16 attitudes. From the 30 most voted elements by the experts, three competencies were proposed: one related to the clinical care, other related to the work process and the last one on service networking. Finally, the elements that were not included in the main list and how they can contribute to the debate about the health professionals, better qualifying them to work in the Unified Health System (SUS), with PSR.

Keywords: Street Offices teams; professional skills; training for the SUS. 